\title{
Antibacterial And Antifungal Effect Of Some Natural Extracts And Their Potential Use As Photosensitizers
}

\author{
Abdullah T. Al-fawwaz,PhD \\ Department of Biological Sciences, Al al-Bayt University, Jordan \\ Khaled A. Al-Khaza'leh,PhD \\ Department of Physics, Al al-Bayt University, Jordan
}

doi: 10.19044/esj.2016.v12n6p147 URL:http://dx.doi.org/10.19044/esj.2016.v12n6p147

\begin{abstract}
One of the threats on the health sector is the appearance of multi antibiotic resistant microorganisms. Thus, this occurs because of using natural and synthetic antimicrobial agents in excessive doses. Now, many scientists all around the world are performing research on natural extracts that have antimicrobial activity using photodynamic therapy (PDT) which involves light activation. The aim of this study, however, is to evaluate the effect of photodynamic antimicrobial chemotherapy using extracts from Pomegranate (Punica granatum), Cinnamon (Cinnamomum verum), Roselle (Hibiscus sabdariffa), Carob (Ceratonia siliqua), and Nigella or black cumin oil (Nigella sativa) against two gram-positive and two gram-negative bacteria (Bacillus cereus, Staphylococcus aureus, Escherichia coli, and Pseudomonas aeruginosa) respectively; and three different fungi (Aspergillus niger, Mucor sp., and Rhizopus sp.), using agar well diffusion method. The prepared methanolic extracts presented absorption between 300 and $-900 \mathrm{~nm}$ wavelengths. The maximum activity of Roselle (Hibiscus sabdariffa) was against Staphylococcus aureus in total darkness with $52.5 \pm$ $2.5 \mathrm{~mm}$ inhibition zone diameter. Also, the most sensitive fungi was Mucor sp. Cinnamon (Cinnamomum verum) extract was with $31.0 \pm 1.0 \mathrm{~mm}$ inhibition zone diameters. The results showed that there was an inhibitory effect of Cinnamon (Cinnamomum verum) and Roselle (Hibiscus sabdariffa) extracts against most of the tested species.
\end{abstract}

Keywords: Antimicrobial, Photosensitizer, Extracts, Fungi

\section{Introduction}

Photosensitizers are compounds used to generate reactive oxygen species in the presence of light and molecular oxygen for the treatment of malignant and non malignant tissues in a medical process called 
photodynamic therapy (Sibata, et al., 2000). Nowadays, several antimicrobial agents are used for the treatment of diseases, but their use is limited by a number of factors. These factors include the increased prevalence of antibiotic resistant bacteria and fungi emerging from the extensive use of antibiotics and high drug toxicity. Therefore, research has focused on new natural antimicrobial agents which have received significant attention lately. Thus, the research on natural products and the search for new therapeutic alternatives for antimicrobials should be supported (Compean and Ynalvez, 2014; Gasparetto et al., 2010).

Consequently, some ancient civilizations have used natural plants in treating some kinds of diseases such as vitiligo, psoriasis, and skin cancer. Indians used the seeds of plant (Psoralea Corylifolia) combined with sunlight to treat psoriasis (Pramilla et al., 2006), leucoderma and leprosy (Kirtikar et al., 1975; Siddiqui and Ansari, 1995; Rangari and Agarwal, 1992). Also, Egyptians used extracts from plants (Ammi Majus) in treating vitiligo (Selim and Ouf, 2012), psoriasis and leukoderma (Hakim,1969; ElMofty, 1948; Fahmy and Abu-Shady, 1948; El-Mofty, 1952). Hence, going back to nature seems to be the best choice to win the war against diseases. This study focuses on the extraction of 5 dyes which were expected to have light sensitizing properties. These dyes are: Pomegranate (Punica granatum), Cinnamon (Cinnamomum verum), Roselle (Hibiscus sabdariffa), Carob (Ceratonia siliqua), and Nigella or black cumin oil (Nigella sativa).

\section{Materials and Methods}

\section{Extraction}

The plants used in this study were nigella seeds oil, pomegranate, Cinnamon, Roselle, and Carob. Nigella seeds oil was bought from the market while the other plants were dried, cut into small pieces, crushed, and then placed in closed vessels. The dried plant powder (150 g) was mixed with $150 \mathrm{ml}$ of methanol at room temperature for $24 \mathrm{~h}$. The extracts were separated by centrifugation for $15 \mathrm{~min}$ at $1500 \mathrm{rpm}$. Methanolic extracts were concentrated to $15 \mathrm{ml}$ using rotary evaporator, and then the concetrated methanolic extract was stored in a refrigerator at $-4^{\circ} \mathrm{C}$ until when needed.

\section{Spectroscopy}

The excitation region of methanolic crude extracts was determined using the absorption spectrum in the 300-900 $\mathrm{nm}$ range. The extracts were evaluated at concentrations of $5 \mathrm{~g} / 100 \mathrm{~mL}$. The absorption spectra were taken with a spectrometer (UNICAM UV/Vis spectrometer, England). Methanol was used as a reference. 


\section{Assessment of Activity}

An antimicrobial activity was tested against four bacterial strains (Escherichia coli, Pseudomonas aeruginosa, Bacillus cereus, and Staph aureus) and three fungal species (Aspergillus niger, Mucor sp., and Rhizopus sp.). The bacterial cultures were cultivated in a nutrient agar and incubated at $37^{\circ} \mathrm{C}$ for 24 hours, while the fungal cultures were cultivated in potato dextrose (PDA) medium at $28^{\circ} \mathrm{C}$ for 72 hours. Furthermore, the colonies were picked by a loop and inoculated in a $10 \mathrm{ml}$ media broth. A serial dilution using the bacterial culture was performed to determine the CFU value per $\mathrm{mL}$. A volume of $100 \mu \mathrm{l}$ of a $\left(1 \times 10^{6}\right)$ dilution factor was inoculated in agar plates by spread plating. A serial dilution using spore suspension in a volume of $0.1 \mathrm{ml}$ containing $1 \times 10^{6}$ spore/ml was inoculated in PDA plates by spread plating. Cefaclor $(5 \mathrm{mg} / \mathrm{ml})$ and fluconazole $(10 \mathrm{mg} / \mathrm{ml})$ were used as standard control of the tested bacteria and fungi, respectively. All experiments were conducted in triplicates. Thus, the results were expressed as average \pm standard deviation (SD) for more accuracy (Alsohaili and Alfawwaz, 2014).

\section{Treatment}

The extracts $(0.5 \mathrm{ml})$ were added to agar, and then was well incubated for 24 or 72 hours at $37^{\circ} \mathrm{C}$ or $28^{\circ} \mathrm{C}$ for bacterial and fungal strains, respectively, under total darkness. The same procedure was repeated under the same conditions with the presence of $100 \mathrm{~W}$ white light. After incubation, the colonies formed on the plates were visually counted. The zones of inhibition were observed and the diameters of inhibition zones were measured. Methanol was used as a control.

\section{Results and Disscusion}

Figure (1) shows that all dyes have a maximum absorption in violet and blue region. Besides, nigella oil has another peak in the red region. Pomegranate dye has a peak at about $370 \mathrm{~nm}$, Cinnamon at 335nm, Roselle at $340 \mathrm{~nm}$, Carob at 330, and nigella oil has two peaks at $460 \mathrm{~nm}$ and $670 \mathrm{~nm}$.

All dyes have maximum absorption in visible light region which means that they could have some photodynamic effects when they are exposed to light. These dyes could be used as photosensitizers after characterization. Red and near infrared lights have a depth of penetration through the skin more than other wavelengths. This makes nigella oil which has a peak in the red region more encouraging to be used in photodynamic therapy. 


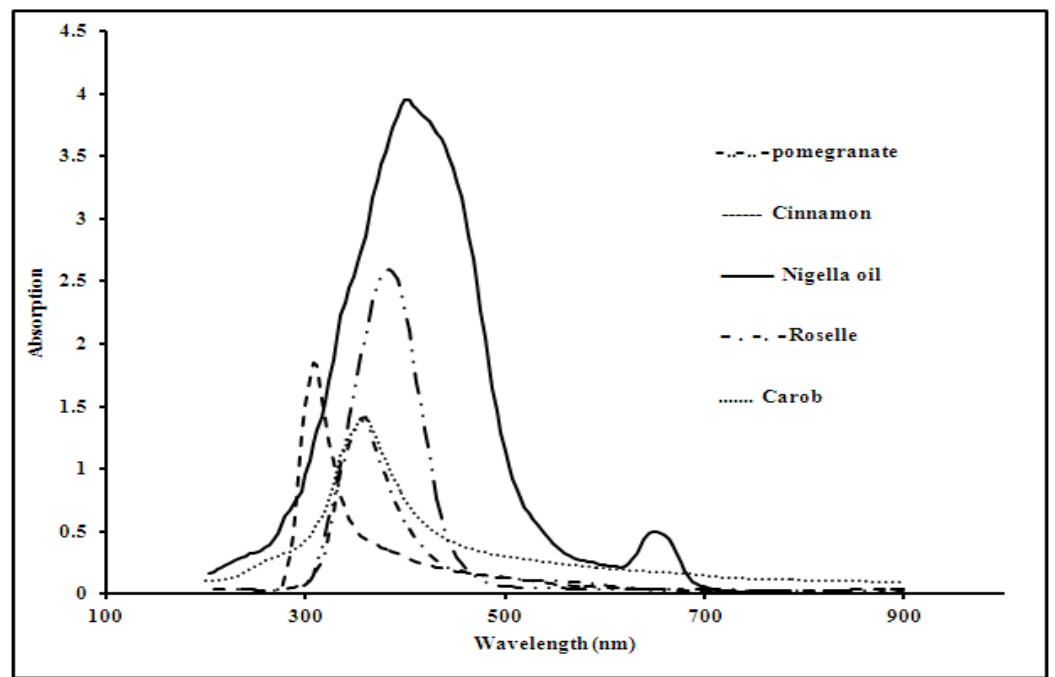

Figure (1). Absorption spectra of methanolic extracts with wavelength in $\mathrm{nm}$.

Figure (2) exhibits the effect of four extracts and nigella oil against $E$. coli species, while Pomegranate and Roselle have no effect on this type of bacteria. However, nigella oil was the most effective. The presence of light slightly decreased the efficiency of these substrates, while Carob has no effect on E. coli with light. Figure (3) shows that cinnamon and nigella oil affected the Pseudomonas aeregnosa species while no effect appeared for Roselle. A slight effect of light appeared on Pomegranate while there was no effect of light on Carob. On the other hand, the presence of the light appeared to increase the effect of nigella oil on this type of species.

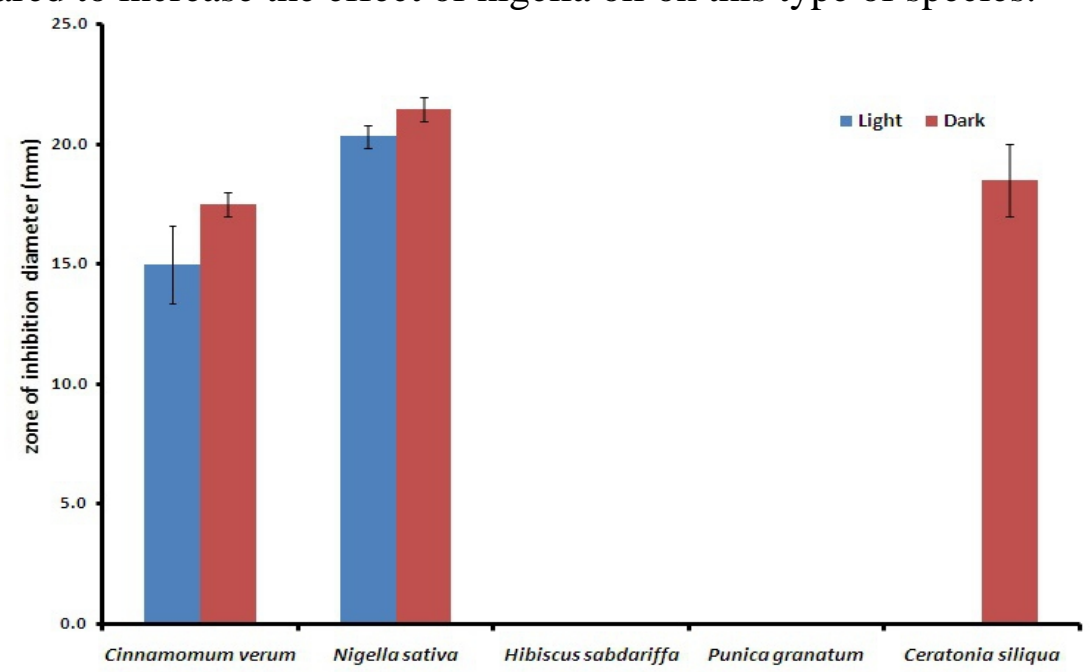

Figure (2). Evaluation of the antibacterial activity of different methanolic plants extract and nigella oil under continuous light and dark conditions, measured as average zone of inhibition diameter $(\mathrm{mm})$ for $E$. coli with respect to their respective control treatment, \pm the standard deviation. 


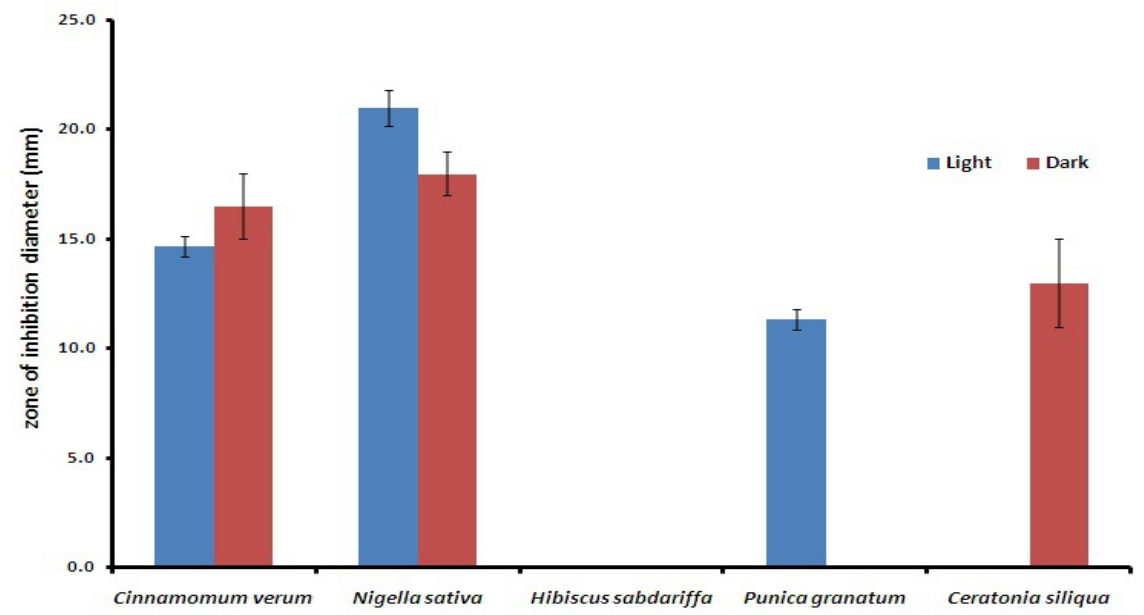

Figure (3). Evaluation of the antibacterial activity of different methanolic plants extract and nigella oil under continuous light and dark conditions, measured as average zone of inhibition diameter (mm) for Pseudomonas aeruginosa with respect to their respective control treatment, \pm the standard deviation.

From figure (4), it can be seen that all the extracts and the nigella oil show different effects on Bacillus cerus species. Antibacterial activity of Roselle in total darkness exhibited a remarkable efficiency in resisting this type of bacteria. On the other hand, Pomegranate and Carob were the least efficient. The presence of light decreased the efficiency of Roselle. Figure (5) also shows the same trend as figure (4) on staph aureus species with more efficiency $(52.5 \pm 2.5 \mathrm{~mm})$ for Roselle incubated under continuous light compared with the efficiency $(42.5 \pm 2.5 \mathrm{~mm})$ in Bacillus cerus.

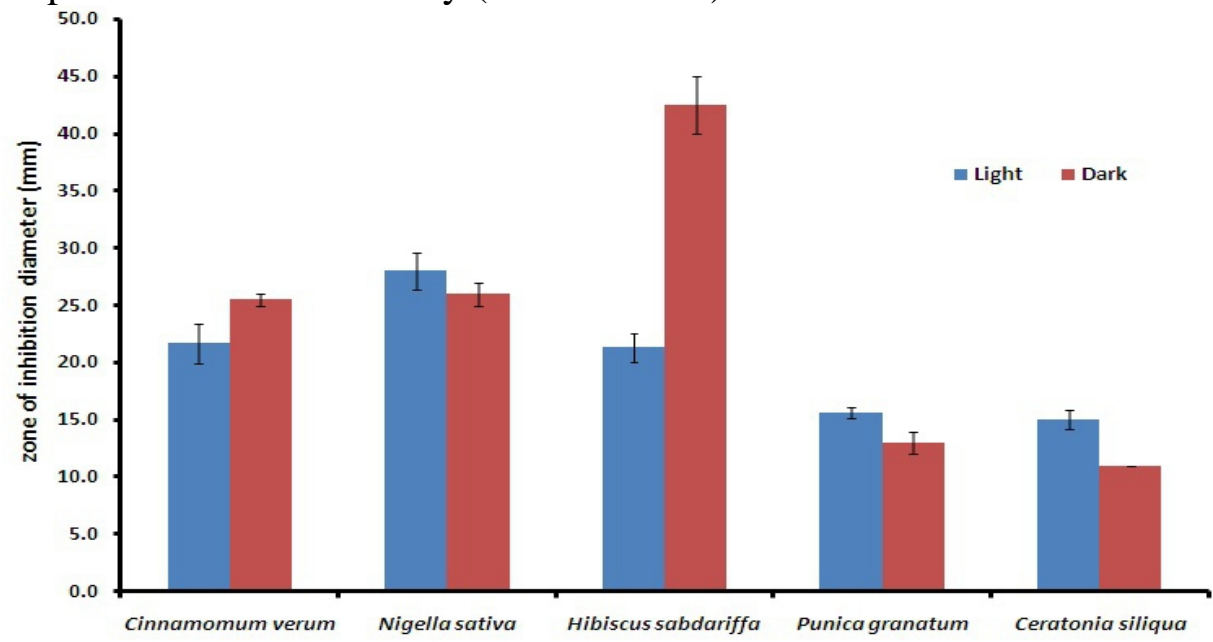

Figure (4). Evaluation of the antibacterial activity of different methanolic plants extract and nigella oil under continuous light and dark conditions, measured as average zone of inhibition diameter $(\mathrm{mm})$ for Bacillus cereus with respect to their respective control treatment, \pm the standard deviation. 


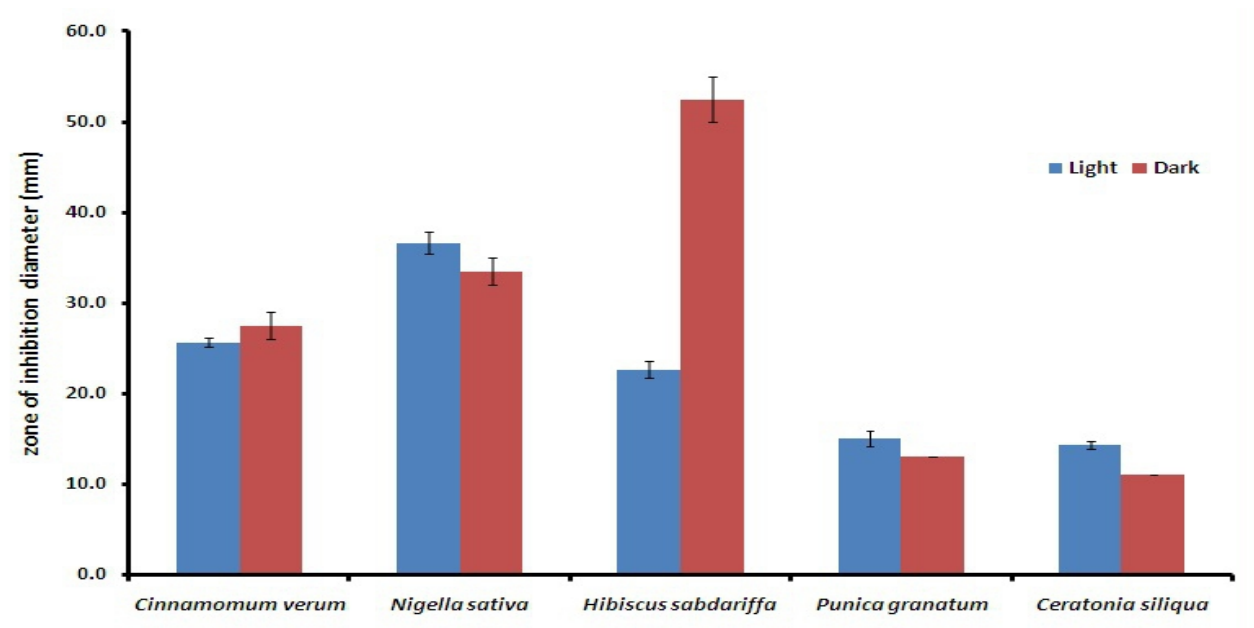

Figure (5). Evaluation of the antibacterial activity of different methanolic plants extract and nigella oil under continuous light and dark conditions, measured as average zone of inhibition diameter ( $\mathrm{mm}$ ) for Staph aureus with respect to their respective control treatment, \pm the standard deviation.

Figures (6-8) shows the effect of four extracts and nigella oil against three fungal species (Aspergillus niger, Mucor sp., and Rhizopus sp.). Figure 6 shows a patent effect of cinnamon on Rhizopus sp.; and there was no activity for Roselle and Pomegranate against Rhizopus sp.. The absence of light slightly increased the efficiency of nigella oil and Carob. All extracts and nigella oil exhibited almost good effects against Mucor sp. as shown in figure 7. Cinnamon and nigella oil shows more activity compared with the others. Thus, the presence of light had no distinguishable effect on activity.

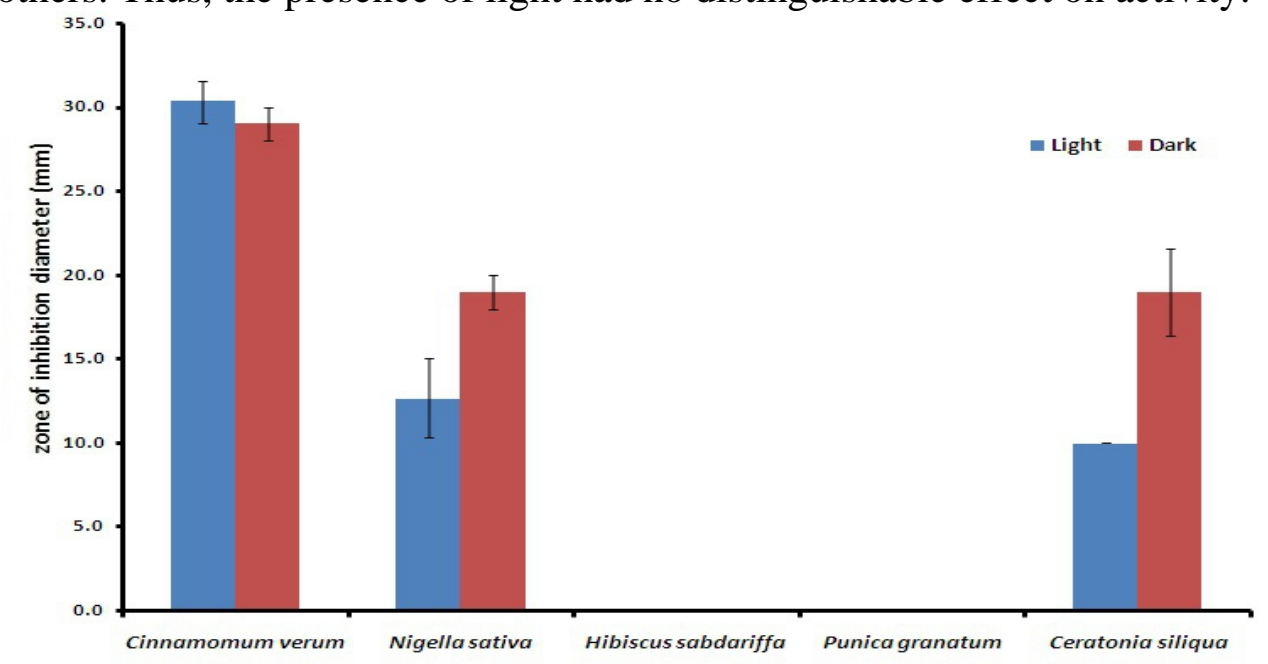

Figure (6). Evaluation of the antifungal activity of different methanolic plants extract and nigella oil under continuous light and dark conditions, measured as average zone of inhibition diameter (mm) for Rhizopus sp. with respect to their respective control treatment, \pm the standard deviation. 


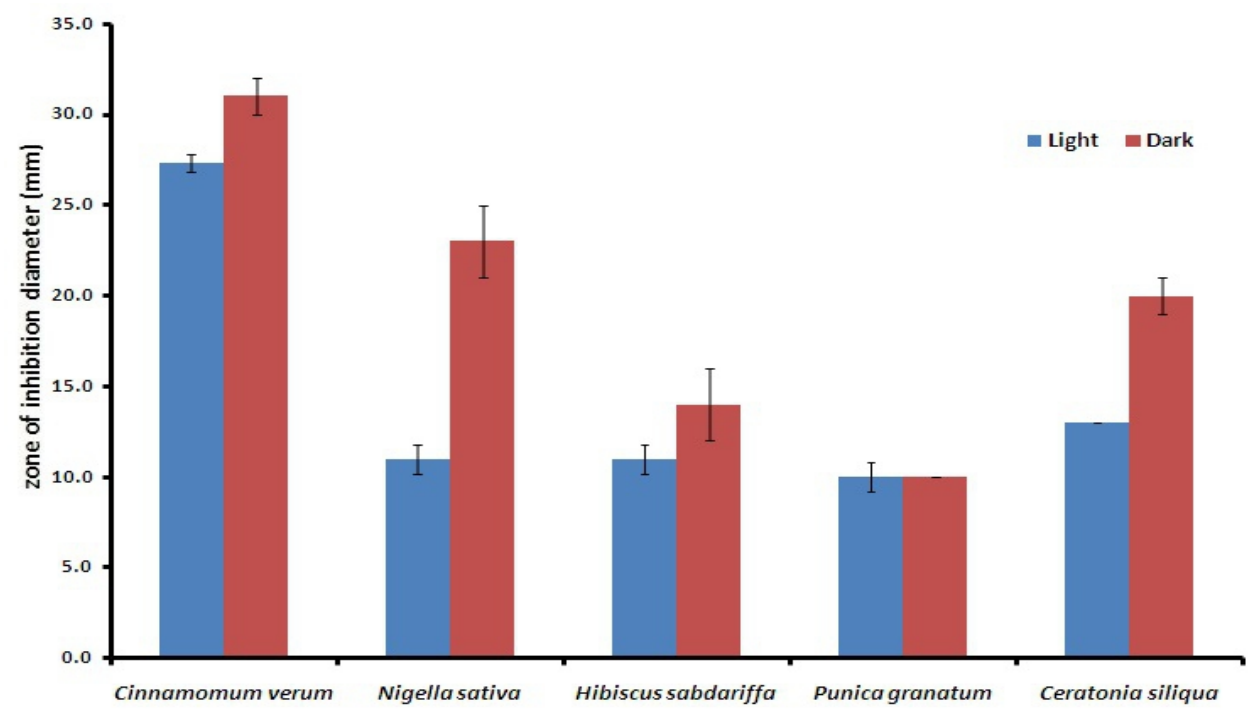

Figure (7). Evaluation of the antifungal activity of different methanolic plants extract and nigella oil under continuous light and dark conditions, measured as average zone of inhibition diameter (mm) for Mucor sp. with respect to their respective control treatment, \pm the standard deviation.

All extracts and nigella oil showed antifungal activity against Aspergillus niger when incubated in total darkness. The maximum activity was 38.0 \pm 2.5 and $22.5 \pm 2.5 \mathrm{~mm}$ for Cinnamon and Carob extracts, respectively, as shown in figure 8 . Incubation under continuous light seems to have a little effect against Aspergillus niger.

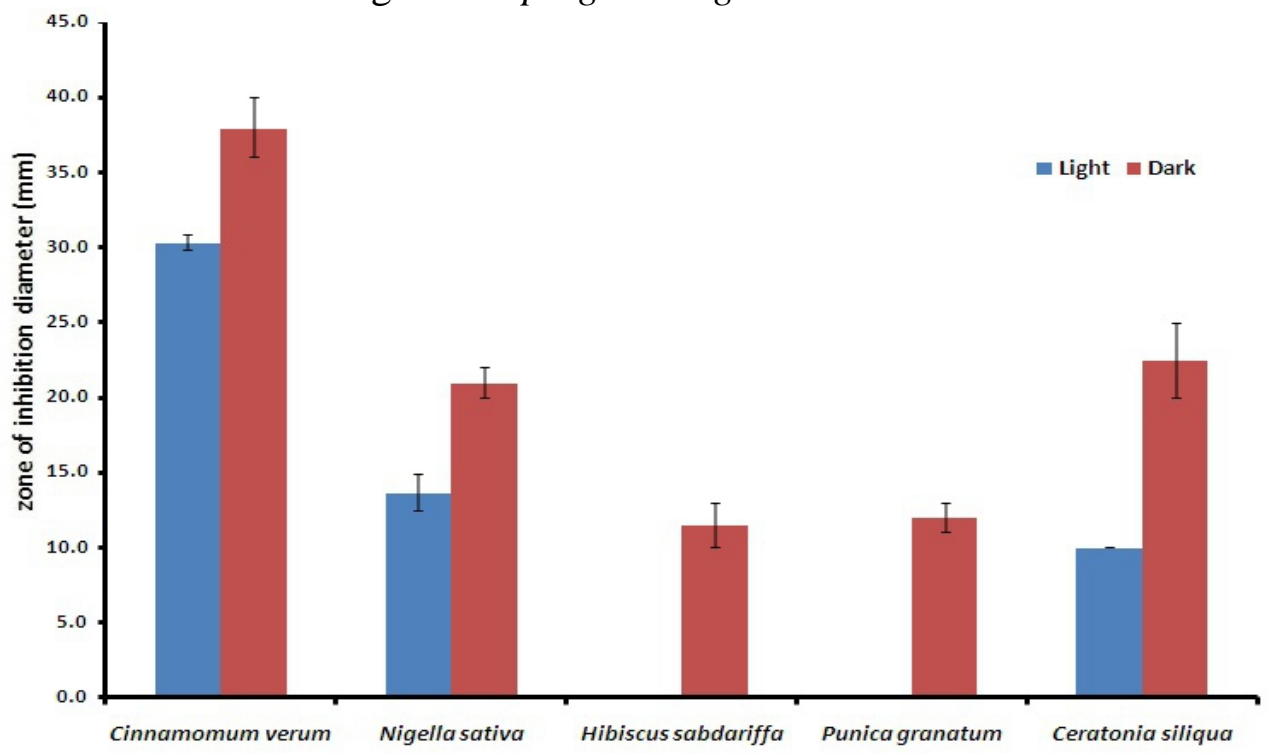

Figure (8). Evaluation of the antifungal activity of different methanolic plants extract and nigella oil under continuous light and dark conditions, measured as average zone of inhibition diameter (mm) for Aspergillus niger with respect to their respective control treatment, \pm the standard deviation. 
From the above figures, it shows that Cinnamon affected all the used bacteria and fungi. Its effect on staph aureus was the best through all bacterial species. Also, it shows the activity against all fungal species. Nigella oil also affected all bacteria and fungal species used. However, with less efficiency, Cinnamon is used against fungal species. Its effect on Bacillus cerus and Staph aureus is more patent than on E. coli and Pseudomonas aeregnosa. Roselle has a remarkable efficiency against Bacillus cerus and Staph aureus bacteria, while it has no activity against $E$. Coli, Pseudomonas aeregnosa, and Rhizopus sp.. Pomegranate and Carob appeared to be the least effective against the use of bacterial and fungal species.

Due to the increase in resistance to traditional antibiotic in bacteria and fungi, there is an urgent need to find alternative antimicrobial therapeutics agents extracted from natural sources. In the present study, the application of light and total darkness to cultures of different gram positive and negative bacteria and fungi using plant extracts and oil as potential photosensitizing agents have showed satisfactory results.

Nigella oil has reported inhibitory effects against bacteria. Akgul (1989) found that low concentrations of nigella oil (black cumin) had antibacterial and antifungal effects. Also, it was found that the fixed oil of black cumin had an inhibitory effect against $S$. aureus and B. cereus (Farrag et al., 2000). Arici et al. (2005) reported that low concentrations of black cumin oil were infective against $E$. coli and some other bacterial species. Hence, this is consistent with our results in this study. Different results were obtained by the methanol extract of cinnamon indicating a negative activity on E. Coli and S. aureus (Senhaji et al., 2004; Mahfuzul Hoquea et al., 2008). It was found that cinnamon suppressed E. coli, Staphylococcus, and Candida albican growth (Farhat et al., 2013).

Khalaphallah and Soliman (2014) found that ethanol extracts of Roselle has more antimicrobial activity than water extracts against Bacillius subtilis, Escherichia coli, and Pseudomonas aeruginosa. Also, it was found that Roselle extracts of high concentration suppressed the bacteria (Chunthanom et al., 2013). Thus, this disagree with our results which showed that methanolic extract of Roselle has antimicrobial activity against gram positive bacteria only and there was no activity against gram negative bacteria. This may be due to the failure of some photosensitizers to produce any killing, which mean that the active agents were unable to diffuse towards the critical target sites of the bacteria (Saw, 2011). Meziani et al. (2015) found that pods extract of Carob has no effect against $P$. atrosepticum while the leaf extracts exhibited potent antimicrobial activity against it. A weak inhibitory action of carob extract against $S$. aureus and $P$. fragi was 
confirmed in broth culture, while little effect was noted with S. enteritidis (Tassou et al., 1997).

Plant extracts and their essential oils consititue secondary metabolites such as Steroids, triterpenes, and polyphenolic compounds such as flavonoids which may have antimicrobial activity (Gasparetto et al., 2010). There is a little studies for the evaluation of photosensitizing agents present in plant extracts and oils. However, more studies are needed to investigate if these secondary metabolites are photoactive. Furthermore, it also shows how we can enhance antimicrobial activity of these plant crude extracts and oils.

\section{Conclusion}

The results from this study show that Nigella oil (Nigella sativa), methanol extract of Pomegranate (Punica granatum), Cinnamon (Cinnamomum verum), Roselle (Hibiscus sabdariffa), and Carob (Ceratonia siliqua) has different antimicrobial activity according to light exposure. The antimicrobial activity may be attributed to the presence of secondary metabolites which may differ according to plant families. Therefore, it exhibits different antimicrobial activities. The extracts of plants are promising as natural antimicrobial agents. Despite these results, further investigations were encouraged to further our knowledge about these compounds to confirm the potential of these natural extracts for application as natural photosensitizers in photodynamic therapy. Antimicrobial photodynamic therapy will become more important in the future as a potential solution of antibiotic resistance problems.

\section{Acknowledgment}

We express our sincere gratitude to Al al-Bayt University for using the facilities at the Department of Biological Sciences and the Department of Physics, In addition, we wish to thank them for their technical and financial assistance during the course of this study.

\section{References:}

Akgul, A. (1989). Antimicrobial activity of black cumin (Nigella sativa L.) essential oil. Gazi Journal of Faculty of Pharmacology, 6, 63-68.

Alsohaili, S.A. \& Al-fawwaz, A.T. (2014). Composition and antimicrobial activity of achillea fragrantissima essential oil using food model media. European Scientific Journal, 10(30), 156-165.

Arici, M., Sagdic, O., \& Gecgel, U. (2005). Antibacterial effect of Turkish black cumin (Nigella sativa L.) oils. Grasas y Aceites. 56(4), 259-262. 
Chunthanom, P., Chaikham, P. \& Intaket, R. (2013). Biochemical and antibacterial properties of Thai medicine herbal infusions. International Food Research Journal, 20(4), 1901-1907.

Compean, K.L., \& Ynalvez, R.A. (2014). Antimicrobial activity of plant secondary metabolites: A Review. Research Journal of Medicinal Plant, 8, 204-213.

El-Mofty, A.M, (1948). A preliminary clinical report on the treatment of leucodermia with Ammi majus Linn. J Egypt Med Assoc, 31, 651-665.

El-Mofty, A.M. (1952). Further study on treatment of leucodermia with Ammi majus Linn. J R Egypt Med Assoc, 35,1-19.

Fahmy, I.R., \& Abu-Shady, H. (1948). The isolation and properties of ammoidin, ammidin and majudin and their effect in the treatment of leukodermia. Q J Pharm Pharmacol, 21,499-503.

Farhat, S.D., Gauri, P., Mamta J., Ruchita, P., \& Shubhangi, W. (2013). A Study of antibacterial effect of some selected essential oils and medicinal herbs against acne causing bacteria. International Journal of Pharmaceutical Science Invention, 2(1), 27-34.

Farrag, H.A., El-Bazza, Z.M., El-Fouly, M.D., \& El-Tablawy, S.M. (2000). Effect of gamma radiation on the bacterial flora of Nigella sativa seeds and its oil constituents. Acta Pharma, 50, 195-207.

Gasparetto, A., Lapinski, T.F., Zamuner, S.R., Khouri, S., Alves, L.P., Munin, E., Salvador, M.J. (2010). Extracts from Alternanthera maritima as natural photosensitizers in photodynamic antimicrobial chemotherapy (PACT). Journal of Photochemistry and Photobiology B: Biology. 99, 1520.

Hakim, R.E. (1969). Rediscovery of a treatment for vitiligo. Clio Medica 4, 277-289.

Kirtikar, K.R. \& Basu, B.D. (1975). In Medicinal Plants (eds Blatter, E., Cains, J.F., Mhaskar, K.S.), Vivek Vihar, New Delhi, p. 536.

Mahfuzul Hoquea, M.d., Barib, M.L., Vijay, K.J., \& Kawamoto S. (2008). Antimicrobial activity of cloves and cinnamon extracts against food borne pathogens and spoilage bacteria, and inactivation of listeria monocytogenes in ground chicken meat with their essential oils. Report of National Food Research Institute , 72, 9-21.

Meziani S., Oomah B.D., Zaidi, F., Simon-Levert, A., Bertrand, Rachida, C., \& Zaidi-Yahiaoui, R. (2015). Antibacterial activity of carob (Ceratonia siliqua L.) extracts against phytopathogenic bacteria Pectobacterium atrosepticum. Microbial Pathogenesis, 78, 95-102.

Pramilla, S., Agarwal, D., \& Garg, S.P. (2006). Isolation and identification of furocoumarins from the seeds of Psoralea corylifolia linn. Indian Journal of pharmaceutical Sciences, 68(6), 768-771. 
Khalaphallah, R., , \& Soliman, W.S. (2014). Effect of henna and roselle extracts on pathogenic bacteria. Asian Pacific Journal of Tropical Disease, 4(4), 292-296

Rangari, V.D. \& Agarwal, S.R. (1992). Chemistry and pharmacology of Psoralea corylifolia. Indian Drugs,29, 662-668.

Selim, Y.A. \& Ouf, Y.A. (2012). Anti-inflammatory new coumarin from the Ammi majus L. Organic and Medicinal Chemistry Letters, 2,1-4.

Saw, L. (2011). Science against microbial pathogens: photodynamic therapy approaches. In: Science against microbial pathogens: Communication Current Research and Technological Advances (Eds.) A. Méndez Vilas. Formatex Research Center, Badajoz, Spain. P. 691.

Senhaji, O., Faid, M., \& Elyachioui, M. (2004). Inhibitory effect of cinnamon extracts on bacterial antibio-resistant strains. Biologie \& Santé, 4(2), 1-10.

Sibata, C.H., Colussi, V.C., Oleinick, N.L. \& Kinsella, T.J. (2000). Photodynamic therapy: a new concept in medical treatment. Brazilian Journal of Medical and Biological Research,33(8), 869-880.

Siddiqui, A.A. \& Ansari, S.H. (1995). Phyto-chemical and pharmacological investigation on Psoralea corylifolia. Hamdard Medicus, 38 (3), 109-115.

Tassou, C.C., Drosinos, E.H., \& Nychas, J.E. (1997). Weak antimicrobial effect of carob (Ceratonia siliqua) extract against food-related bacteria in culture media and model food systems, World Journal of Microbiology and Biotechnology, 13(4), 479-481. 